\title{
RAPID AND REPEATED BOLUS DRUG DELIVERY ENABLED BY HIGH EFFICIENCY ELECTROCHEMICAL BELLOWS ACTUATORS
}

\author{
R. Sheybani, H. Gensler, and E. Meng
}

Biomedical Microsystems Laboratory, University of Southern California, Los Angeles, CA, USA

\begin{abstract}
For the first time, rapid and repeatable delivery of precise drug boluses (up to 4015 -second boluses of 19.12 $\pm 0.73 \mu \mathrm{L}$ cocaine within 50 minutes) is achieved with a high efficiency MEMS electrolysis actuator. Gas bubble recombination parameters and drug viscosity were investigated. Nafion ${ }^{\mathbb{B}}$-coated electrodes provided superior pumping performance (linearity and repeatability) compared to uncoated electrodes.
\end{abstract}

\section{KEYWORDS}

Bolus drug delivery, drug pump, electrochemical actuators, Nafion ${ }^{\circledR}$ polymer coating.

\section{INTRODUCTION}

Mechanical pumps operating under the principle of electrolytically generated pneumatic actuation enable many interesting biological and medical applications due to their low power consumption, low heat generation, accurate flow control, large driving force, biocompatible construction and potential for wireless actuation [1].

Electrolysis dissociates water into hydrogen and oxygen gas [2]. When a potential is applied to an electrochemical cell consisting of a pair of electrodes in contact with water as the electrolyte, reactions occur at both electrodes. At the anode, water is dissociated into oxygen gas, cations and electrons, following:

$$
\begin{gathered}
\boldsymbol{H}_{2} \mathrm{O}(\boldsymbol{l}) \underset{\mathrm{E}^{\circ}}{\rightleftarrows}\left(25^{\circ} \mathrm{C}\right)=1.23 \mathrm{~V} \\
\boldsymbol{H}^{+}(\boldsymbol{a q})+\mathbf{2} \boldsymbol{e}^{-}+\mathbf{0 . 5 \boldsymbol { O } _ { 2 }}(\boldsymbol{g}) \\
=1
\end{gathered}
$$

The protons are driven through the electrolyte to the cathode where they combine with the electrons traveling through the external circuit to form hydrogen gas:

$$
\begin{aligned}
\mathbf{2} \boldsymbol{H}^{+}(\boldsymbol{a q})+\mathbf{2} \boldsymbol{e}^{-} & \underset{\boldsymbol{H}_{2}}{(\boldsymbol{g})} \\
\mathrm{E}^{\circ}\left(25^{\circ} \mathrm{C}\right) & =0.00 \mathrm{~V}
\end{aligned}
$$

The net electrolysis reaction is:

$$
\boldsymbol{H}_{\mathbf{2}} \mathrm{O}(\boldsymbol{l}) \underset{\mathrm{E}^{\circ}}{\stackrel{\left(25^{\circ} \mathrm{C}\right)}{\rightleftarrows} \boldsymbol{H}_{2}(\boldsymbol{g})+\mathbf{0 . 5} \mathbf{5 O}_{2}(\boldsymbol{g})}
$$

and entails a 3:2 stoichiometric ratio of gas to liquid and occurs via the transfer of four equivalents of electrons through an external circuit [3]. Generated gases result in large volume expansion which can be harnessed for actuation and thus pumping [1]. The fluid to be pumped can be directly electrolyzed, however, it is also possible to separate the reaction from the fluid to be pumped. This is accomplished by containing the electrochemical reaction in a chamber having a flexible wall that is adjacent to the fluid to be pumped.
Experimentally, generated gas bubbles may occlude the active electrode surface and prevent contact with the electrolyte (water) which then leads to a lower pumping efficiency. Nafion ${ }^{\circledR}$, a polymer electrolyte coating possessing high gas solubility, prevents bubble occlusion on the surface of the Pt electrode by allowing rapid diffusion of gases away from the catalyst surface and results in a $20 \%$ increase in current density [5].

However, the hydrophobic fluorocarbon backbone of Nafion ${ }^{\circledR}$ is electrochemically inactive and may block part of the Pt catalyst surface area, thus reducing the effective surface area of Nafion $^{\circledR}$ coated Pt electrode by $86 \%$ compared to that of the native, uncoated Pt electrode [5]. The coating layer needs to be thick enough to provide sufficient effective reaction sites at the interface between Pt and the Nafion ${ }^{\mathbb{B}}$ coating. Optimal performance was reported for coatings composed of less than 9 wt. \% Nafion ${ }^{\circledR}$. Performance degradation at $>9$ wt. $\%$ Nafion is attributed to the increasing resistance to gas diffusion into the electrode or gas desorption from the electrode [6].

Once the current is removed, the gases recombine through the reverse reactions to form water. However, due to the large activation overpotential of oxygen reduction, an electrocatalyst like $\mathrm{Pt}$ is required [7]. The recombination mechanism for Nafion $^{\circledR}$ coated and uncoated electrodes is studied here.

Improved efficiency of electrolysis pumping electrodes coated with Nafion ${ }^{\circledR}$ (flow rates of up to 141 $\mu \mathrm{L} / \mathrm{min}$ at $13 \mathrm{~mA}$ ) was reported previously [8]. Here, we report an actuator consisting of an electrolyte-filled Parylene bellows and these improved electrodes for drug delivery applications. Specifically, our focus is rapid and repeatable delivery of drug boluses (one $\sim 100 \mu \mathrm{L}$ dose per minute) to meet requirements for drug addiction studies in mice using a novel self-administration paradigm.

\section{DESIGN}

The pumping mechanism for bolus delivery is as follows: constant current applied to the electrode pair results in electrolysis and a pressure increase that inflates the bellows which then expels drug from an adjacent reservoir through a delivery catheter (Fig. 1). The current magnitude and application time can be adjusted to obtain the desired bolus volume delivery and administration time. Once the current is turned off, the produced gases recombine to form water again, allowing the bellows to deflate to its original position. Pumping cycles between $\mathrm{ON}$ and OFF modes then ceases when all the water is electrolyzed or should be terminated when the bellows is fully expanded.

The Parylene bellows separates the electrolysis reaction so that the drug is not electrolyzed or diluted by the electrolyte (DI water) and the hydrogen and oxygen 
gases produced. This configuration also prevents gases from entering the body through the catheter which could potentially have harmful consequences.
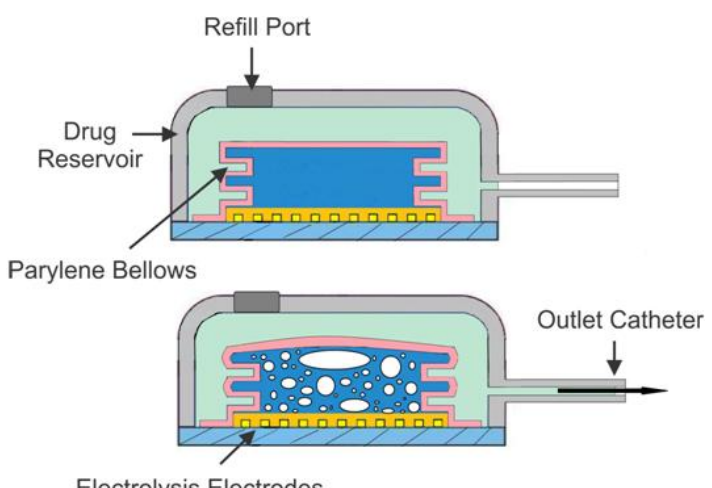

Electrolysis Electrodes

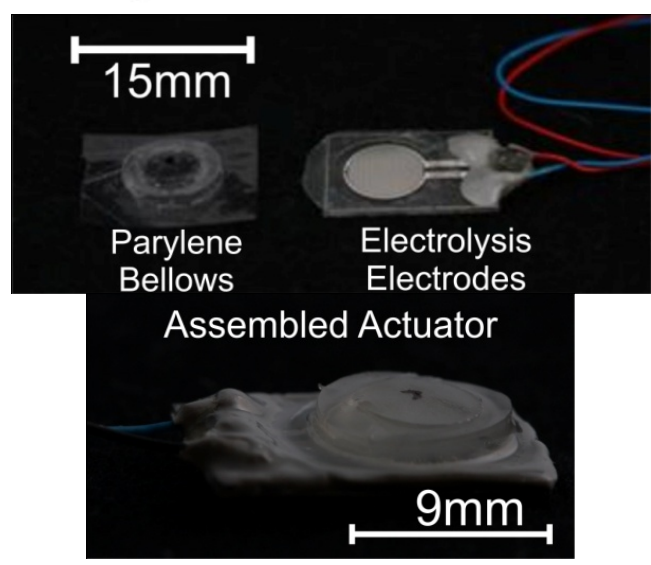

Figure 1: Electrochemical actuator with drug separating bellows: (a) operation concept; (b) fabricated Pt electrode on glass substrate and assembled actuator consisting of bellows, electrolyte, and electrodes.

\section{FABRICATION}

Interdigitated Pt electrodes (100 mm wide elements separated by $100 \mathrm{~mm}$ gaps, $8 \mathrm{~mm}$ diameter footprint, 300 $\AA / 2000 \AA \mathrm{Ti} / \mathrm{Pt}$ ) were fabricated on soda lime substrates by liftoff [1]. The electrodes were then potentiostatically cleaned at $\pm 0.5 \mathrm{~V}$ (Gamry Reference 600 Potentiostat, Warminster, PA) in $1 \mathrm{X}$ phosphate buffered saline. To produce a $1 \mu \mathrm{m}$ thick coating, Nafion ${ }^{\circledR}$ (Dupont DE521 Solution, Ion Power, INC, New Castle, DE) was applied to the electrodes by dip coating twice [8].

Parylene bellows (1, 1.5, and 2 convolutions; $9 \mathrm{~mm}$ diameter) were fabricated as described in [9] and then filled with DI water and combined with the Nafion ${ }^{\circledR}$ coated interdigitated $\mathrm{Pt}$ electrodes using double-sided pressure sensitive adhesive film (3M $\mathrm{M}^{\mathrm{TM}}$ Double Coated Tape 415, 3M, St. Paul, MN). The seal was further reinforced with marine epoxy (Loctite, Westlake, $\mathrm{OH}$ ).

\section{EXPERIMENTS AND RESULTS Actuator Characterization}

Flow rates were measured by clamping the actuator in a test fixture filled with water and weighing pumped water accumulated over 2 minutes for each bellows configuration (maximum flow rate $100.6 \pm 1.11 \mu \mathrm{L} / \mathrm{min}$ for 1.5 convolution bellows at $10 \mathrm{~mA}$ ). High flow rates acceptable for rapid bolus dosing were achieved for all configurations (Fig. 2).

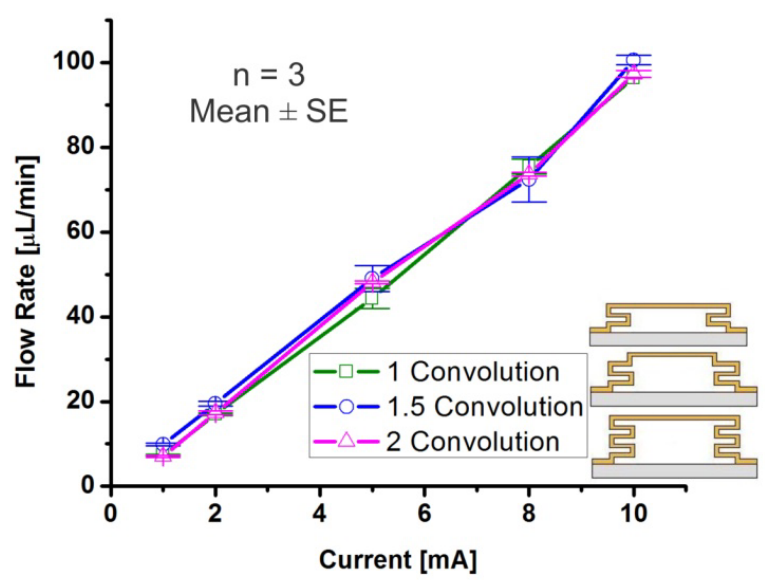

Figure 2: Current controlled flow delivery with different bellows configurations performed in a custom test fixture.

Flow rates obtained are listed in Table 1. As expected, the three bellows configurations had similar flow rates. Bellows were operated below the elastic limit and did not undergo plastic deformation. However, the one convolution bellows was irreversibly damaged during the testing at $10 \mathrm{~mA} .2$ convolution bellows were chosen for further testing due to their higher deliverable volume [9].

Table 1: Flow rate values for 1, 1.5, and 2 convolutions Parylene Bellows.

\begin{tabular}{|c|c|c|c|}
\hline \multirow{2}{*}{$\begin{array}{c}\text { Current } \\
{[\mathrm{mA}]}\end{array}$} & \multicolumn{3}{|c|}{ Flow Rate $[\mu \mathrm{L} / \mathrm{min}]$} \\
\cline { 2 - 4 } & $\begin{array}{c}1 \\
\text { Convolution }\end{array}$ & $\begin{array}{c}1.5 \\
\text { Convolution }\end{array}$ & $\begin{array}{c}2 \\
\text { Convolution }\end{array}$ \\
\hline 1 & $7.33 \pm 0.17$ & $9.88 \pm 0.31$ & $7.04 \pm 0.29$ \\
\hline 2 & $17 \pm 0.29$ & $19.54 \pm 0.54$ & $17.33 \pm 0.44$ \\
\hline 5 & $44.33 \pm 2.42$ & $49.05 \pm 3.05$ & $48.17 \pm 0.33$ \\
\hline 8 & $75.5 \pm 1.80$ & $72.44 \pm 5.35$ & $73.66 \pm 0.44$ \\
\hline 10 & N/A & $100.61 \pm 1.11$ & $87.33 \pm 0.83$ \\
\hline
\end{tabular}

\section{Recombination Studies}

Bolus delivery requires power cycling, thus recombination is an important factor. Recombination of gas bubbles to water commences once current is removed. Recombination rate was measured in uncoated and Nafion ${ }^{\circledR}$-coated electrodes (Fig. 3). Electrodes were clamped in the test fixture, filled with water, and operated without bellows. Different gas volumes were generated by varying the current application time $(10 \mathrm{~mA}$ constant current). When turned on, the electrode-only actuator pumped water through a calibrated $100 \mu \mathrm{L}$ pipette and forward displacement of the liquid front was observed. Recombination volume was calculated based on the observed backwards displacement of the liquid front after the pump was turned off.

For uncoated $\mathrm{Pt}$ electrodes, recombination is dependent on factors such as available reaction sites and 
the slow diffusion of oxygen atoms through water [10]. In Nafion ${ }^{\circledR}$ coated electrodes, recombination proceeds faster in comparison to uncoated ones. This is attributed to the rapid diffusion of gas through the Nafion [5] which likely sets up a gas concentration gradient in water which drives the diffusion of gases to the Nafion surface. The more efficient generation of gas may also contribute to the greater recombination rate. At a sufficiently high gas volume, the Nafion $^{\circledR}$ becomes saturated and recombination is reaction limited (as opposed to diffusion limited). These regimes are apparent in Fig. 4 in which the actuator $\left(\right.$ Nafion ${ }^{B}$ coated electrode integrated with 2 convolution bellows) was clamped in a test fixture filled with water and repeatedly turned ON and OFF in 15 second and 1 minute intervals, respectively $(10 \mathrm{~mA}$ constant current). Recombination rate was observed to increase (downward slope in OFF cycle) to a maximum. Repeatable and accurate delivery of 40 boluses (19.12 \pm $0.73 \mu \mathrm{L}$ ) over 50 minutes was demonstrated.

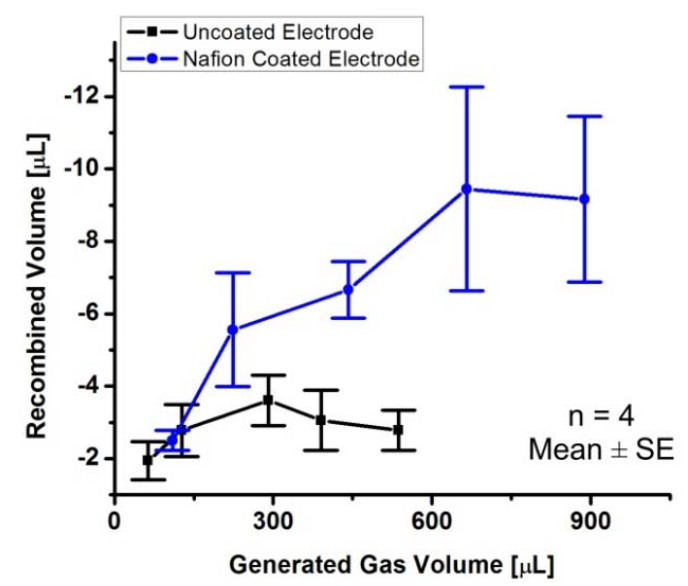

Figure 3: Comparison between recombined volume for uncoated and coated electrodes (current controlled flow rate delivery at $10 \mathrm{~mA}$ ).

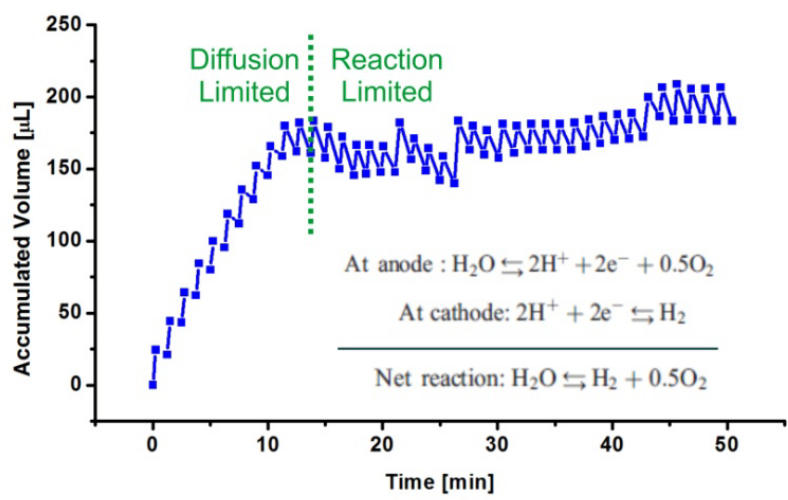

Figure 4: Actuator ON/OFF test with coated electrodes and 2 convolution bellows (at $10 \mathrm{~mA}$ ).

\section{Rapidfire Bolus Delivery}

Rapidfire delivery of 3 boluses at $10 \mathrm{~mA}$ ( 15 seconds ON, 10 seconds OFF) separated by 5 minute OFF cycles was demonstrated (Fig. 5a) with repeatable dosing $(25 \pm 0.6 \mu \mathrm{L}$; Fig. $5 \mathrm{a}$ inset). Fig. $5 \mathrm{~b}$ demonstrates the linear relationship between recombination flow rate and remaining drug volume which confirms the diffusion limited mechanism for this study.

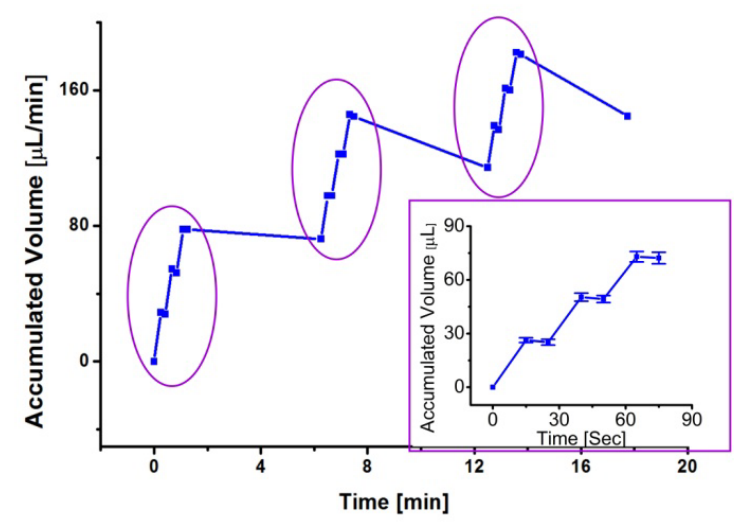

(a)

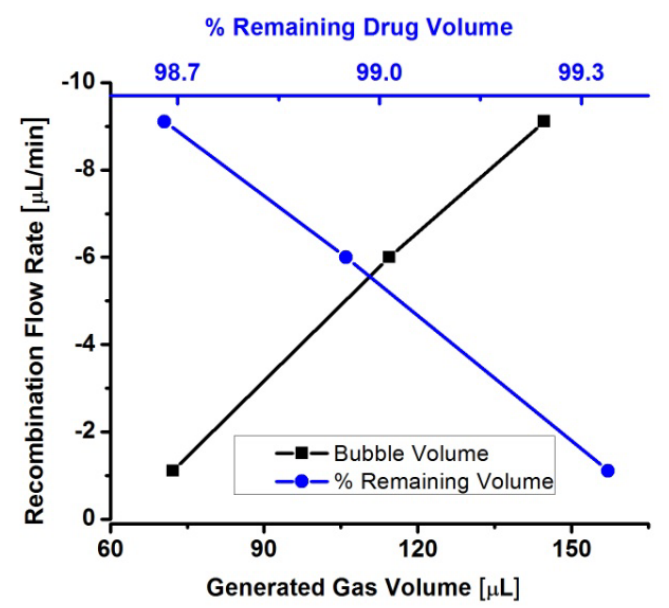

(b)

Figure 5: Rapidfire bolus delivery with actuator (2 convolution bellows, at $10 \mathrm{~mA}$ ): (a) $15 \mathrm{sec}$ ON/10 sec OFF with 5 minute gaps (inset shows repeatability of delivery) and (b) recombination rate linear with generated gas volume.

\section{Nafion ${ }^{\circledR}$ Coating}

Bolus delivery and recombination were studied in uncoated and Nafion ${ }^{\circledR}$-coated actuators with attached Parylene bellows (Fig. 6). In [8], Nafion ${ }^{\circledR}$ coating was shown to result in higher linear flow rates for electrode-only actuators. This was confirmed with the integrated bellows. In the electrode-only case, the polymer coating facilitates recombination and avoids high pressure buildup that would eventually result in irreversible mechanical failure (both tearing and plastic deformation) of the bellows (data not shown).

\section{Drug Concentration and Viscosity}

A $300 \mu \mathrm{L}$ silicone rubber reservoir was integrated with the actuator to form a drug pump and study the effects of drug concentration (and effectively viscosity) on flow rate. Cocaine was dissolved in $0.9 \mathrm{M}$ saline to obtain five different concentrations $(0.0,12.4,14.0$, $15.33,25.73 \mathrm{mg} / \mathrm{mL}$ ). Solutions were loaded into the 
drug reservoir via syringe and pumped. As expected, flow rate decreased with increasing cocaine concentration (Fig. 7).

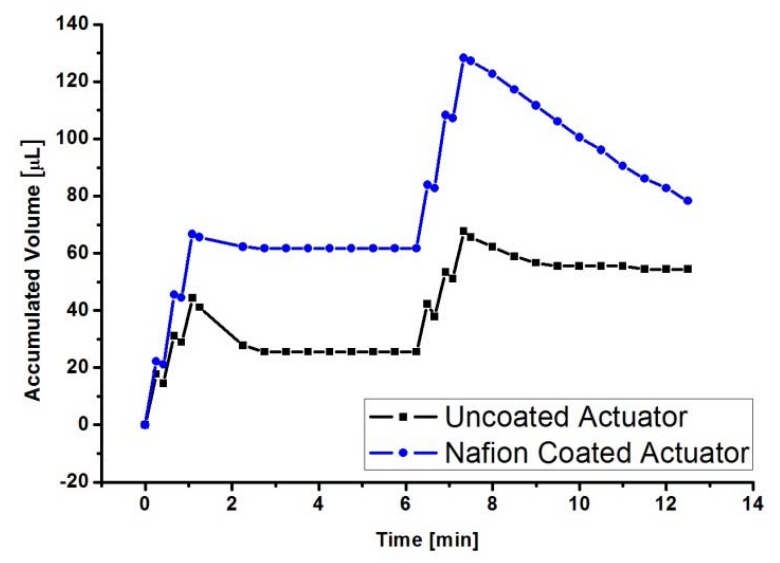

Figure 6: Pumping using uncoated vs. coated actuator: polymer coating enables higher flow rate and predictable recombination (at $10 \mathrm{~mA}, 2$ convolution bellows).

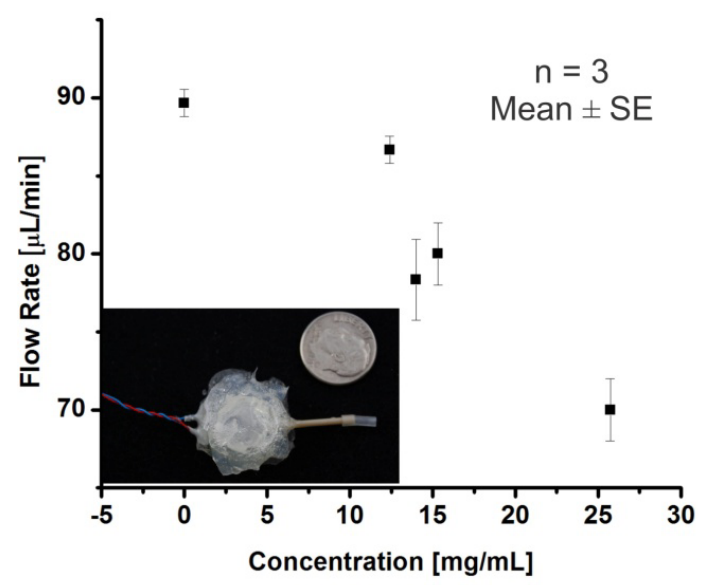

Figure 7: Current controlled flow delivery of Cocaine (in 0.9M saline) loaded in a pump at different concentrations (at $8 \mathrm{~mA}$, 1.5 convolution bellows).

\section{CONCLUSION}

We demonstrated high efficiency MEMS electrolysis actuators capable of rapid and repeatable delivery of precise drug boluses. Gas bubble recombination parameters and drug viscosity were investigated. Nafion ${ }^{\circledR}$-coated electrodes provided superior pumping performance (linearity and repeatability) for pumping and recombination compared to uncoated electrodes. Future work will entail integration of wireless power transfer [8] to enable tetherless self-administration of cocaine boluses for drug addiction studies in freely-behaving mice.

\section{ACKNOWLEDGEMENTS}

This work was funded in part by a Wallace H. Coulter Foundation Early Career Translational Research Award and NIH/NIDA under award number R21DA026970. An OAI Model $30 \mathrm{UV}$ light source was used in the fabrication of the electrodes featured in this work. The authors would like to thank Dr. D. Holschneider, Dr. J.M. Maarek, and the members of the USC Biomedical Microsystems Laboratory for their assistance with this project.

\section{REFERENCES}

[1] P.Y. Li, R. Sheybani, C. Gutierrez, J.T.W. Kuo, and E. Meng, "A Parylene Bellows Electrochemical Actuator", J. Microelectromech. Syst., 19, pp. 215-228, 2010.

[2] P. Choi, D. G. Bessaraboy, R. Datta, "A Simple Model for Solid Polymer Electrolyte (SPE) Water Electrolysis", Solid State Ionics, 175, pp. 535-539, 2004.

[3] C. G. Cameron and M. S. Freund, "Electrolytic actuators: Alternative, high-performance, material-based devices," Proceedings of the National Academy of Sciences of the United States of America, vol. 99, 2002, pp. 7827-7831.

[4] D. E. Lee, S. A. Soper, and W. Wang, "Fabrication and mathematical analysis of an electrochemical microactuator (ECM) using electrodes coated with platinum nano-particles", Microsystem Technologies, 16, pp. 381-390, 2010.

[5] J. Maruyama, M. Inaba, K. Katakura, Z. Ogumi, and Z. Takehara, "Influence of Nafion ${ }^{\circledR}$ film on the kinetics of anodic hydrogen oxidation", $J$. Electroanal. Chem., 447, pp. 201-209, 1998.

[6] T. Ioroi, K. Yasuda, Z. Siroma, N. Fujiwara, and Y. Miyazaki, "Thin film electrocatalyst layer for unitized regenerative polymer electrolyte fuel cells", Journal of Power Sources 112, pp 583-587, 2002.

[7] E. Yeager, "Electrocatlysts for $\mathrm{O} 2$ reduction", Electrochemica Acta, 29, pp.1527-1537, 1984.

[8] R. Sheybani, and E. Meng, "High efficiency Wireless Electrochemical Actuators: Design, Fabrication and Characterization by Electrochemical Impedance Spectroscopy", MEMS Conference, Jan 23-27, 2011.

[9] H.Gensler, R. Sheybani, and E. Meng, "Rapid Non-Lithography Based Fabrication Process and Characterization of Parylene $\mathrm{C}$ Bellows for Applications in MEMS Electrochemical Actuators", The 16th International Conference on Solid-State Sensors, Actuators and Microsystems, June 5-9, 2011, accepted.

[10]L.K. Verheij, "Kinetic modeling of the hydrogen-oxygen reaction on $\mathrm{Pt}$ (111) at low temperature (<170 K)", Surface Science 371, pp. 100-110, 1997.

[11]K. Broka, and P. Ekdunge, "Oxygen and Hydrogen Permeation Properties and Water Uptake of Nafion ${ }^{\circledR}$ 117 Membrane and Recast Film for PEM Fuel Cell”, Journal of Applied Electrochemistry, 27, pp. 117-123, 1997.

\section{CONTACT}

* R. Sheybani, tel: 1-213-821-3949; rsheyban@USC.edu 